\title{
Vertical Motion Determined Using Satellite Altimetry and Tide Gauges
}

\author{
Chung-Yen Kuo ${ }^{1, *}$, C. K. Shum ${ }^{2}$, Alexander Braun ${ }^{3}$, Kai-Chien Cheng ${ }^{4}$, and Yuchan $\mathrm{Yi}^{2}$ \\ ${ }^{1}$ Department of Geomatics, National Cheng-Kung University, Tainan, Taiwan, ROC \\ ${ }^{2}$ Geodetic Science, School of Earth Sciences, The Ohio State University, Columbus, USA \\ ${ }^{3}$ Department of Geomatics Engineering, Schulich School of Engineering, University of Calgary, Calgary, Canada \\ ${ }^{4}$ Department of Earth and Environmental Sciences, National Chung Cheng University, Chiayi, Taiwan, ROC
}

Received 15 November 2006, accepted 9 July 2007

\begin{abstract}
A robust method to estimate vertical crustal motions by combining geocentric sea level measurements from decadal (1992 - 2003) TOPEX/POSEIDON satellite altimetry and long-term (> 40 years) relative sea level records from tide gauges using a novel Gauss-Markov stochastic adjustment model is presented. These results represent an improvement over a prior study (Kuo et al. 2004) in Fennoscandia, where the observed vertical motions are primarily attributed to the incomplete Glacial Isostatic Adjustment (GIA) in the region since the Last Glacial Maximum (LGM). The stochastic adjustment algorithm and results include a fully-populated a priori covariance matrix. The algorithm was extended to estimate vertical motion at tide gauge locations near open seas and around semi-enclosed seas and lakes. Estimation of nonlinear vertical motions, which could result from co- and postseismic deformations, has also been incorporated. The estimated uncertainties for the vertical motion solutions in coastal regions of the Baltic Sea and around the Great Lakes are in general $<0.5 \mathrm{~mm} \mathrm{yr}^{-1}$, which is a significant improvement over existing studies. In the Baltic Sea, the comparisons of the vertical motion solution with 10 collocated GPS radial rates and with the BIFROST GIA model show differences of $0.2 \pm 0.9$ and $1.6 \pm 1.8 \mathrm{~mm} \mathrm{yr}^{-1}$, respectively. For the Great Lakes region, the comparisons with the ICE-3G model and with the relative vertical motion estimated using tide gauges only (Mainville and Craymer 2005) show differences of $-0.2 \pm 0.6$ and $-0.1 \pm 0.5 \mathrm{~mm} \mathrm{yr}^{-1}$, respectively. The Alaskan vertical motion solutions (linear and nonlinear models) have an estimated uncertainty of $\sim 1.2-1.6 \mathrm{~mm} \mathrm{yr}^{-1}$, which agree qualitatively with GPS velocity and tide gauge-only solutions (Larsen et al. 2003). This innovative technique could potentially provide improved estimates of the vertical motion globally where long-term tide gauge records exist.
\end{abstract}

Key words: Vertical motion, Tide gauge, Altimeter

Citation: Kuo, C. Y., C. K. Shum, A. Braun, K. C. Cheng, and Y. Yi, 2008: Vertical motion determined using satellite altimetry and tide gauges. Terr. Atmos. Ocean. Sci., 19, 21-35, doi: 10.3319/TAO.2008.19.1-2.21(SA)

\section{INTRODUCTION}

Relative sea level change is the variation in the position of the mean sea surface relative to the solid Earth, or a benchmark on the crust of the solid Earth referenced to the tide gauge instrument. In most parts of the world, benchmark locations to which tide gauges are referenced are subject to Earth deformation processes such as earthquakes and their deformation cycles, tectonic plate motion, basin evolution, Glacial Isostatic Adjustment (GIA), and anthropogenic effects such as local subsidence due to water extraction, mining, oil or natural gas drilling. Therefore, the signals of tide

\footnotetext{
* Corresponding author

E-mail:kuo70@mail.ncku.edu.tw
}

gauge records contain both sea level change and vertical crustal motion.

Deformation processes have various spatio-temporal scales and thus affect observations of sea level using different tide gauges. Deformation processes can be episodic or continuous. For example, the interseismic deformation before an earthquake depends on the tectonic setting and can have both elastic and viscous components. The coseismic offset of an earthquake is almost completely elastic and the deformation reaches equilibrium after a few weeks. The postseismic deformation is predominantly caused by viscous relaxation. Viscoelastic processes like GIA can persist for several thousand years and contribute to continuous rather than episodic deformations. Plate tectonics, including 
the subduction of lithospheric plates, represent one of the solid Earth deformation signals potentially affecting tide gauge sea level measurements. Thus, different temporal scales require a thorough analysis of the impact of deformations (in particular the vertical component) on the sea level measurements from tide gauge records. The relative vertical motion of the solid Earth's surface, which is relative to a chosen benchmark, can be determined by means of strandlines, historic tide gauge records (Mäkinen and Saaranen 1998; Larsen et al. 2003) and precise leveling (Mäkinen and Saaranen 1998). The geocentric vertical motion, which is relative to the center of the Earth, can be determined by means of absolute gravimeters (Pagiatakis and Salib 2003), GPS (Johansson et al. 2002; Caccamise et al. 2005), satellite laser ranging, DORIS Doppler tracking system, and the combination of tide gauge and altimetry data with uncertainties in excess of $2 \mathrm{~mm} \mathrm{yr}^{-1}$ (Cazenave et al. 1999; Lin 2000; Nerem and Mitchum 2002).

Shum et al. (2002) and Kuo et al. (2004) developed a novel technique, which uses historic tide gauge records and a decade of TOPEX/POSEIDON (T/P) altimeter data in a stochastic adjustment for the Baltic Sea and the Great Lakes regions to improve the vertical motion estimates. The method demonstrated significantly reduced solution uncertainties compared with other studies, such as by Nerem and Mitchum (2002), where estimated vertical crustal motions are provided with accuracies of $1-2 \mathrm{~mm} \mathrm{yr}^{-1}$ or larger. This latter approach involved computing the sea level differences between 114 tide gauges and T/P altimetry over one decade. In this study, the improved adjustment algorithm for estimating vertical motion is presented in detail. This includes an extension of the algorithm (Kuo et al. 2004) to apply to open ocean regions, such as the Alaskan coast, and a model to include nonlinear vertical motion due in part to co- or postseismic deformation. Results of the estimated vertical motion solutions are provided for three regions, namely the Baltic Sea, the Great Lakes, and Alaskan coastal region. These estimates are then compared to independent observations and geophysical models. The ability to improve vertical motion solutions near the vicinity of long term tide gauges should eventually enhance the accuracy of sea level change estimates.

\section{DATA ANALYSIS}

In this study, 1-Hz Geophysical Data Record (GDR) data products observed by TOPEX Side A (TSA) and Side B (TSB) altimeters, onboard the TOPEX/POSEIDON (T/P) mission for 10-day repeat cycle 4 through cycle 364 were used. The POSEIDON altimeter data were not used, nor were the data after the $\mathrm{T} / \mathrm{P}$ orbit was changed into the Tandem Mission phase. The T/P data, available from the NASA/JPL Physical Oceanography Distributed Active Archive Center (PO.DAAC) in the Generation B Merged T/P
Geophysical Data Record (MGDR-B) as global sea surface height measurements, are then processed in the form of sea surface height anomalies using the Ohio State University (OSU) stackfile database methodology (Kruizinga 1997). The instrument corrections, media corrections (unsmoothed dual-frequency ionosphere, TOPEX Microwave Radiometer (TMR) wet troposphere correction, and dry troposphere correction), geophysical corrections (solid Earth and ocean tides, tidal loading, pole tide, the BM4 sea state bias or SSB model augmented by a SSB correction model (Chambers et al. 2003), Wallops drift correction for the TOPEX range, and correction for the TMR drift (V. Zlotnicki, personal communication) have been applied. The inverted barometer (IB) corrections were not applied. The ocean tide correction is not applied to TOPEX data in the Great Lakes analysis because tides in the Great Lakes are largely negligible.

In the Baltic Sea region, monthly averaged tide gauge data of 25 stations referred to the Revised Local Reference (RLR), which is defined to be approximately $7000 \mathrm{~mm}$ below mean sea level at each station, obtained from the Permanent Service for Mean Sea Level (PSMSL) are used in the study (Fig. 1) (Woodworth and Player 2003). The longest record covers a time span from 1811 to 1999 . This analysis used data records which ended in 2001 and all records used herein are at least 40 years long.

For the Great Lakes region, daily water level gauge records of 29 stations in the USA published by the Center for Operational Oceanographic Products and Services (CO-OPS) and 22 stations in Canada from the Marine Environmental Data Service (MEDS) are employed. The International Great Lakes Datum 85 (IGLD85) is the common datum for all water level gauges in the Great Lakes (Fig. 2, circles denote water level gauge locations). The IGLD85 heights must be converted to Helmert orthometric heights (Hofmann-Wellenhof and Moritz 2006) in order to make comparisons with the TOPEX data. The conversion of water gauge records from IGLD85 heights to orthometric heights is an approximately $1: 1$ ratio (Cheng et al. 2008), which does not significantly affect estimates of vertical motion. For instance, the average change rate of the differences in form of time series between two height systems (IGLD85 and orthometric heights) at Holland West, Lake Michigan, is smaller than $0.05 \mathrm{~mm} \mathrm{yr}^{-1}$, which is smaller than the uncertainties of the estimated vertical motion. Therefore, neglecting the transformation from IGLD85 heights to Helmert orthometric heights should not affect the determination of absolute vertical motion within the targeted accuracy.

For the Alaska region, monthly averaged RLR tide gauge data of 15 stations around South Alaska from PSMSL are used in this study (denoted by circles and triangles in Fig. 3 for their locations). The record with the longest time span is from 1909 to 2002. The latest record in this analysis ended in 2002 and all records used are in excess of 30 years except for the Sand Point and Kodiak stations. 


\section{VERTICAL MOTION ADJUSTMENT: ALGO- RITHMS AND RESULTS}

\subsection{Algorithm for Semi-Enclosed Basins}

The rates of relative and absolute sea level changes measured by tide gauges, $\dot{S}$, and by altimeters, $\dot{g}$, can be expressed as follows:

$$
\begin{aligned}
& \dot{S}(\lambda, \varphi)=\dot{T}(\lambda, \varphi)+\dot{t}_{\text {error }}(\lambda, \varphi)-\dot{u}(\lambda, \varphi) \\
& \dot{g}(\lambda, \varphi)=\dot{T}(\lambda, \varphi)+\dot{a}_{\text {error }}(\lambda, \varphi)
\end{aligned}
$$

where $\lambda$ is the longitude, $\varphi$ is the co-latitude, $\bullet$ denotes the secular rate, $\dot{T}(\lambda, \varphi)$ are all physical contributions to absolute sea level variations, for example, steric sea level and ocean mass variation, $\dot{u}(\lambda, \varphi)$ is the absolute vertical motion rate, $\dot{t}_{\text {error }}(\lambda, \varphi)$ is the tide gauge error, and $\dot{a}_{\text {error }}(\lambda, \varphi)$ is the altimetry error (e.g., drift). It is assumed that the drift errors associated with both instruments, which are inseparable from the signals of absolute sea level and vertical motion,

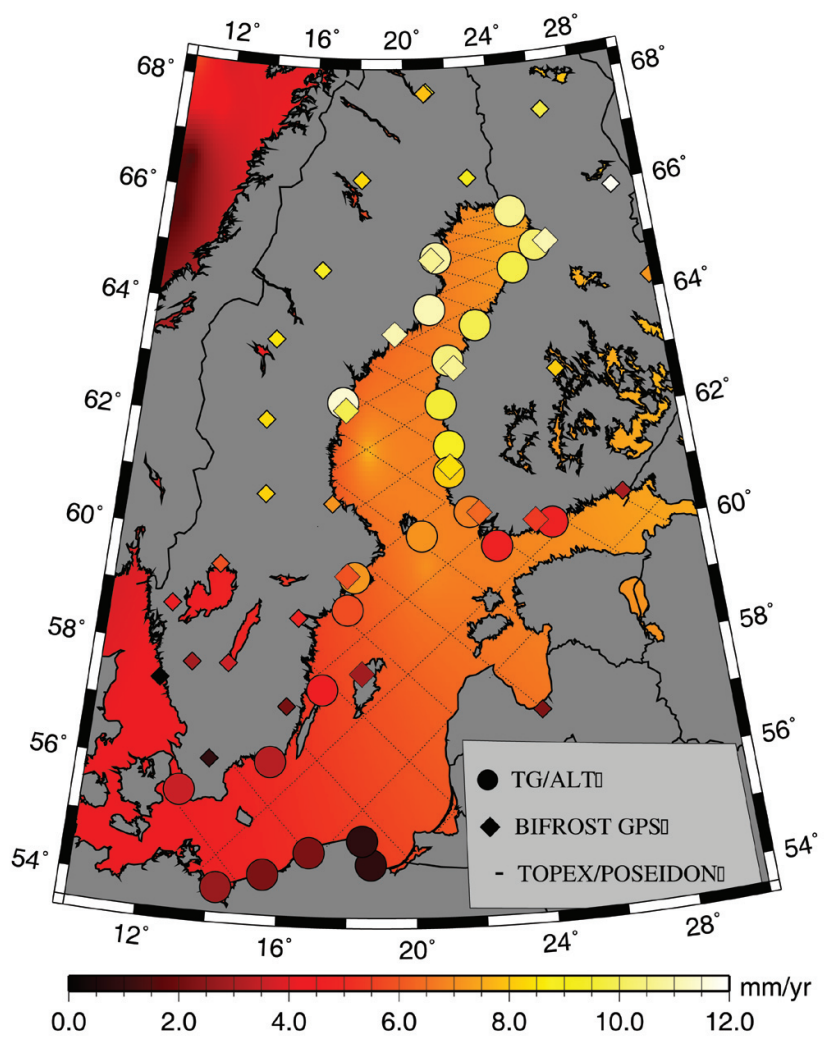

Fig. 1. Estimated vertical motion (circles) at 25 tide gauge stations around the Baltic Sea improved from (Kuo et al. 2004), and the $10 \mathrm{col}-$ lected GPS solutions (big diamonds) of the BIFROST project around gauge stations (Johansson et al. 2002). Dotted line in the background shows the nominal ground tracks of TOPEX/POSEIDON and background color represents sea level trends derived from 1992 - 2001 TOPEX/POSEIDON, which are not uniform in the Baltic Sea. BIFROST GPS vertical rates from inland stations (small diamonds) are also shown.
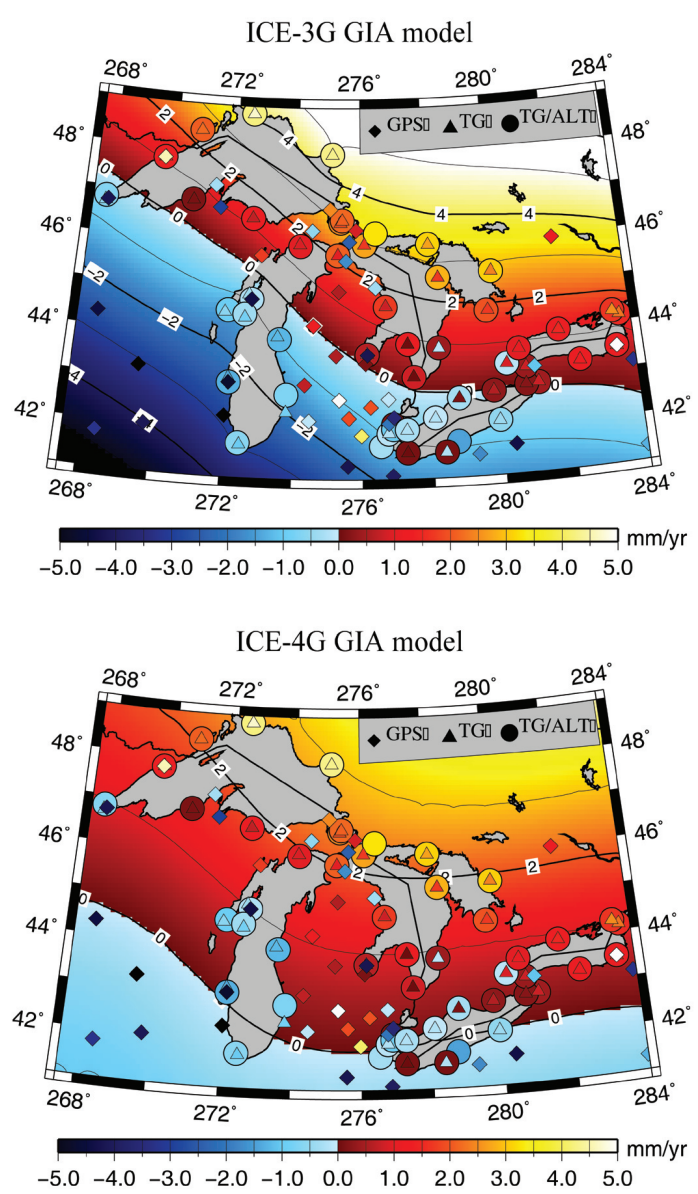

Fig. 2. Estimates of absolute vertical motion (circles) at 51 water level gauge sites in the Great Lakes by combining TOPEX/POSEIDON decadal altimeter data and long-term water level gauge records. The diamonds are GPS velocities (NGS solution, M. Cline and R. Snay, personal communications, 2004). The triangles present the vertical motions from water level gauge only analysis (Mainville and Craymer 2005). The background of the top panel shows vertical motions predicted by the ICE-3G GIA model (Tushingham and Peltier 1991), while the background of the bottom panel is from the ICE-4G GIA model (Peltier 2002).

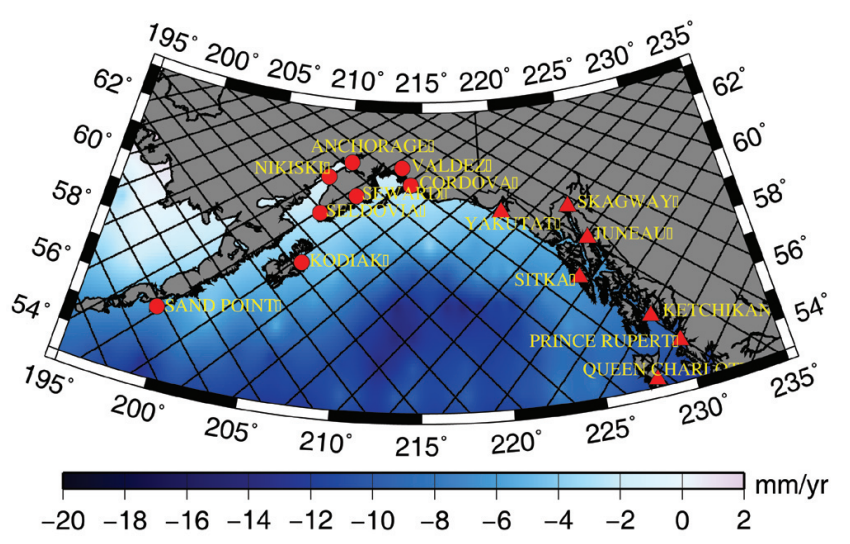

Fig. 3. Tide gauge stations in Alaska. All tide gauges are separated into two regions, region I (triangles) and region II (circles). The background is altimetric sea level changes derived from Geosat, ERS-1, ERS-2, and TOPEX/POSEIDON from 1985 to 2003 with a data gap for $1988-1991$. 
are small and negligible, i.e., $\dot{a}_{e r r o r}(\lambda, \varphi)$ is ignored. The assumption is valid because all known TOPEX corrections (including TMR drift) have been applied and we used the PSMSL's Revised Local Reference (RLR) tide gauge records, which have been processed to remove known biases and jumps. In addition, because we difference altimetry and tide gauge records, common errors such as the atmospheric inverted barometer effect on the sea level are largely diminished. Accordingly, an estimated rate of absolute vertical motion follows through the simple rearrangement of Eq. (1) (Kuo et al. 2004):

$\dot{u}(\lambda, \varphi)=\dot{g}(\lambda, \varphi)-\dot{S}(\lambda, \varphi)$

In order to reduce the random noise of altimetric data and tide gauge records and to diminish discrepancies between the data, spatial and temporal averages are employed to produce the time series of absolute sea level change implied by the TOPEX altimeter data. For instance, if the study area is a semi-enclosed or enclosed ocean, TOPEX data and all tide gauge records are averaged to monthly time series over the whole basin (Kuo et al. 2004). According to Eq. (2), the averaged absolute vertical motion could be computed as the difference of average change rates estimated by fitting both time series individually using a least squares approach. However, in practice, we fit the differenced time series in order to avoid errors due to data gaps, which vary for different data sets. Therefore, tide gauge records that correspond to the time span of available altimetry data are presently used in the algorithm. However, the current time span of $\mathrm{T} / \mathrm{P}$ data is too short ( 1 decade) to derive an accurate trend because the time series contains seasonal, interannual, decadal, interdecadal, or longer signals, causing the estimated uncertainty to be larger than $1-2 \mathrm{~mm} \mathrm{yr}^{-1}$ (Lin 2000; Nerem and Mitchum 2002).

The following formulation is used to compute relative vertical motion between two adjacent tide gauges based on Eq. (2) to take advantage of any available long historic tide gauge records, thereby reducing the solution uncertainty. The uncertainties of relative vertical motions are small compared to the uncertainties of absolute vertical motion in Eq. (2) because of the long time series of the tide gauges. The rate of relative vertical motion can be expressed as:

$$
\begin{aligned}
r \dot{u}_{i j} & =\dot{u}_{i}\left(\lambda_{i}, \varphi_{i}\right)-\dot{u}_{j}\left(\lambda_{j}, \varphi_{j}\right) \\
& =\dot{g}_{i}\left(\lambda_{i}, \varphi_{i}\right)-\dot{S}_{i}\left(\lambda_{i}, \varphi_{i}\right)-\dot{g}_{j}\left(\lambda_{j}, \varphi_{j}\right)+\dot{S}_{j}\left(\lambda_{j}, \varphi_{j}\right)
\end{aligned}
$$

where $i$ and $j$ are indices of tide gauge stations. In order to simplify the algorithm, $\dot{g}_{i}\left(\lambda_{i}, \varphi_{i}\right)$ and $\dot{g}_{j}\left(\lambda_{j}, \varphi_{j}\right)$ are assumed to be identical and thus the two terms are canceled in Eq. (3). This assumption holds true in semi-enclosed, enclosed seas or in open oceans because sea level change for the adjacent tide gauges are indeed highly correlated. Accordingly, $r \dot{u}_{i j}$ can be achieved by a straight fit of the differences of tide gauge records $i$ and $j$.

A straightforward extension of the Gauss-Markov (GM) model with stochastic constraints is implemented to achieve the best estimate of vertical motion by combining both Eqs. (2) and (3) (e.g., Koch 1999):

$$
\begin{aligned}
& {\left[\begin{array}{l}
y_{1} \\
z_{0}
\end{array}\right]_{(n+l) \times 1}=\left[\begin{array}{l}
A_{1} \\
K
\end{array}\right]_{(n+l) \times m} \xi+\left[\begin{array}{l}
e_{1} \\
e_{0}
\end{array}\right]} \\
& \text { with }\left[\begin{array}{l}
e_{1} \\
e_{0}
\end{array}\right] \sim\left(\left[\begin{array}{l}
0 \\
0
\end{array}\right], \sigma_{0}^{2} P^{-1}=\Sigma\right) \text { and rank }\left[\begin{array}{c}
A_{1} \\
K
\end{array}\right]=m
\end{aligned}
$$

where $m$ is the size of the state vector, $\xi ; l$ is the number of constraint equations or the so-called pseudo-observations, $z_{0} ; n$ is the number of observation vectors, $y_{1} ; A_{1}$ is the observation-state relationship or the design matrix; $e_{1}$ and $e_{0}$ are random error vectors and their expected values are taken as zero; $K$ is the design matrix for the constraint equation; $\sigma_{0}^{2}$ is the unknown a priori variance associated with a weight matrix, $P$, and $\Sigma$ is the variance-covariance matrix. In the computation procedure, $z_{0}$ and $y_{1}$ can be substituted by $\dot{u}(\lambda, \varphi)$ of Eq. (2) and $r \dot{u}_{i j}$ of Eq. (3), respectively. Subsequently, Eq. (4) simplifies to:

$y=A \xi+e \quad$ with $e \sim\left(0, \sigma_{0}^{2} P^{-1}=\Sigma\right)$

where $y$ are the observations substituted by absolute or geocentric vertical motion, $\dot{u}(\lambda, \varphi)$, and relative vertical motion, $r \dot{u}_{i j}$, and $\xi$ is the geocentric vertical motion to be estimated.

The solution of Eq. (5) by the Best Linear Unbiased Estimation procedure has the following form:

$\xi=\left(A^{T} P A\right)^{-1}\left(A^{T} P y\right)$

$\hat{D}\{\hat{\xi}\}=\hat{\sigma}_{0}^{2}\left(A^{T} P A\right)^{-1}$

with $\hat{\sigma}_{0}^{2}=\left(y^{T} P y-A^{T} P y \hat{\xi}\right) /(n-m+l)$

where $\hat{\sigma}_{0}^{2}$ is the estimate of variance $\sigma_{0}^{2}$; and $\hat{D}\{\hat{\xi}\}$ is the dispersion matrix of the estimate, $\hat{\xi}$. Square roots of the diagonal elements of $\hat{D}\{\hat{\xi}\}$ are the formal standard errors of the corresponding estimates, $\hat{\xi}$.

Therefore, the improved technique can be implemented to estimate the rates of the geocentric vertical motions at tide gauge stations by taking advantage of historic tide gauge records and altimetric sea level variations. This is a significant improvement which overcomes the limitations 
of the conventional method, which uses only one decade of satellite altimetry and tide gauge data and is limited to observations within the same data span; a key factor in the resulting reduced uncertainties.

\subsection{Vertical Motion in Fennoscandia}

The procedure by Kuo et al. (2004) is followed herein, with an updated algorithm designed to use a fully-populated a priori variance-covariance matrix instead of a diagonal matrix. Correlations between observations in the adjustment model have been taken into account. The variance-covariance matrix is decomposed as follows:

$\Sigma=\left[\begin{array}{ll}\sum_{0} & \Sigma_{2} \\ \sum_{2} & \Sigma_{1}\end{array}\right]$

The diagonal elements of $\Sigma_{0}=\sigma_{v 2, i j}^{2}+\sigma_{v 3}^{2}$; The off-diagonal elements of $\sum_{0}=\sqrt{\left(\sigma_{v 2, i j}^{2}+\sigma_{v 3}^{2}\right)\left(\sigma_{v 2, j k}^{2}+\sigma_{v 3}^{2}\right)} \times 0.3 ; \sum_{1}=\sigma_{v 1}^{2}$; $\Sigma_{2}=\sqrt{\sigma_{v 1, i}^{2}\left(\sigma_{v 2, i j}^{2}+\sigma_{v 3}^{2}\right)} \times 0.1$

where $i$ and $j$ refer to tide gauge stations. $\sigma_{v 1}$ is the standard deviation of the averaged absolute vertical motion. $\sigma_{v 2, i j}$ is the standard deviation of the computed relative vertical motion between stations $i$ and $j$ [Eq. (3)]; $\sigma_{v 3}$ is the a priori error in the computed relative vertical motion, which is directly related to the uncertainty of the sea level determination using tide gauges. Here, we adopted the uncertainty of the observed sea level rise reported by Douglas (2001), $1.8 \pm 0.4 \mathrm{~mm} \mathrm{yr}^{-1}$, to model $\sigma_{v 3}$ (Kuo et al. 2004). Because any choice of $\sigma_{v 3}$ from $0.3-0.6 \mathrm{~mm} \mathrm{yr}^{-1}$ has resulted in negligible change in the estimates, we simply set $\sigma_{v 3}$ to $0.5 \mathrm{~mm}$ $\mathrm{yr}^{-1}$. If observations are uncorrelated in an adjustment approach, the off-diagonal elements of the $\Sigma_{0}$ matrix are taken as zero. However, it is not true in this study because the observations may be computed using the same tide gauge records. For example, the relative vertical motions $r \dot{u}_{i j}$ and $r \dot{u}_{j k}$ are derived from tide gauges, $i, k$, and the identical station, $j$, so the relative vertical motions considered as observations are correlated and the correlation coefficient is set empirically equal to 0.3 . Similarly, the correlation coefficient between the derived relative and absolute vertical motions, $r \dot{u}_{i j}$ and $\dot{u}_{i}$, as a result of using the identical station, $i$, is set empirically equal to 0.1 to represent the $\Sigma_{2}$ matrix.

The fourth column in Table 1 shows the estimated vertical motion with formal errors at $1.5-8.3 \mathrm{~mm} \mathrm{yr}^{-1}$ by the traditional method according to Eq. (2), and highly correlated time series with correlation coefficients at $0.87 \sim 0.98$. The adjustment approach is first applied to tide gauge records and altimeter data covering years 1992 to 2001. The averaged absolute vertical motion observation computed over the Baltic Sea region using TOPEX and tide gauge data (1992 - 2001) is $6.7 \pm 1.4 \mathrm{~mm} \mathrm{yr}^{-1}$, which will then be used as the constraint and the variance $\left[z_{0}\right.$ in Eq. (4) and $\sigma_{v 1}$ in Eq. (8)] in the improved algorithm. Table 1 (Column 5) shows the absolute vertical motion solutions with the associated uncertainties using the adjustment method. The uncertainties reduce dramatically to $1.4 \mathrm{~mm} \mathrm{yr}^{-1}$ compared with the earlier approach. In addition, the vertical motion solutions were drastically modified from the original and adjusted methods, with differences up to $9 \mathrm{~mm} \mathrm{yr}^{-1}$ and spatially smoother results than those obtained using the first method. Overall, this corresponds to a better agreement qualitatively with GIA model predictions.

Finally, the improved vertical motion solution has a range of $1-12 \mathrm{~mm} \mathrm{yr}^{-1}$, with an average uncertainty estimated at $0.5 \mathrm{~mm} \mathrm{yr}^{-1}(1 \sigma$, Column 6 in Table 1) using tide gauge data over 40 years $(\sim 1950$ - 2001) and TOPEX geocentric sea level data (1992 - 2001). Figure 1 shows a comparison between the estimated vertical motions at 25 tide gauge stations around the Baltic Sea and the collected GPS solutions of the BIFROST project around gauge stations (Johansson et al. 2002). The dotted line in the background shows the nominal ground tracks of TOPEX and the background colour represents sea level change rates derived from 1992 - 2001 TOPEX, which is not uniform in the Baltic Sea. Figure 4 indicates our estimates have an excellent agreement with 10 independently derived GPS rates around tide gauges with a mean difference of $0.2 \pm 0.9 \mathrm{~mm} \mathrm{yr}^{-1}$ and a maximum difference of $2.6 \mathrm{~mm} \mathrm{yr}^{-1}$. In addition to instrumental errors, the tide gauges and BIFROST GPS stations are not necessarily collocated at exactly the same location. The small mean difference provides a validation of both techniques and places bounds on the instrumental stability.

The estimated absolute vertical motion in Fig. 1 clearly reflects a GIA pattern in Fennoscandia (Milne et al. 2001). GIA is ongoing vertical motion after the deglaciation phase finished at about 9 kyrs Before Present (BP), and peaks at $\sim 11 \mathrm{~mm} \mathrm{yr}^{-1}$ in the Gulf of Bothnia and declines towards zero at the perimeter of the former ice sheet. Therefore, independent observations such as GPS and altimeter-tide gauges derived vertical motion can constrain GIA models through a comparison of observations and qualitative GIA estimations. As an example, Milne et al. (2001) derived numerical predictions of vertical motions in GIA models using various Earth model parameters by means of a comparison with BIFROST GPS estimates of 3-D crustal motion. Table 2 shows a comparison of our estimated vertical motion at 25 stations with GIA models, together with ICE-4G deglaciation ice history (Peltier 2002) and the ice history adopted by Milne et al. (2001). The comparison with the BIFROST GIA model indicates a smaller mean difference of $1.4 \mathrm{~mm} \mathrm{yr}^{-1}$ while the comparison with the ICE-4G GIA model shows a mean difference of $3.4 \mathrm{~mm} \mathrm{yr}^{-1}$. Our estimates agree well with BIFROST GIA model because the BIFROST GIA model is constrained by GPS solutions in Fennoscandia. This new technique has the potential to constrain such GIA 
Table 1. Estimated vertical motion derived from decadal TOPEX/POSEIDON altimetry and long-term ( $>40$ years) tide gauge records around the Baltic Sea.

\begin{tabular}{|c|c|c|c|c|c|}
\hline $\begin{array}{l}\text { Latitude } \\
\text { (Degree) }\end{array}$ & $\begin{array}{c}\text { Longitude } \\
\text { (Degree) }\end{array}$ & Data Span & $\begin{array}{c}\text { Altimeter Minus Tide } \\
\text { gauge Solution }^{1} \\
\left(\mathbf{m m} \mathbf{y r}^{-1}\right) \\
1992-2001\end{array}$ & $\begin{array}{c}\underset{\left(\mathrm{mm} \mathrm{yr}^{-1}\right)}{\text { Adjustment }^{2}} \\
1992-2001\end{array}$ & $\begin{array}{c}\text { Adjustment }^{3} \\
\left(\mathbf{m m} \mathbf{y r}^{-1}\right) \\
\text { All Data }\end{array}$ \\
\hline 55.52 & 12.90 & $1930-2001$ & $3.6 \pm 3.0(0.90)$ & $5.5 \pm 1.6$ & $3.3 \pm 0.5$ \\
\hline 56.10 & 15.58 & $1887-2001$ & $6.3 \pm 2.2(0.94)$ & $4.5 \pm 1.4$ & $2.9 \pm 0.5$ \\
\hline 57.37 & 17.10 & $1887-2001$ & $4.5 \pm 2.6(0.92)$ & $3.5 \pm 1.4$ & $4.6 \pm 0.5$ \\
\hline 58.75 & 17.87 & $1887-2001$ & $4.0 \pm 1.5(0.98)$ & $3.5 \pm 1.4$ & $5.9 \pm 0.5$ \\
\hline 59.32 & 18.08 & $1889-2001$ & $2.0 \pm 1.6(0.98)$ & $3.5 \pm 1.3$ & $7.2 \pm 0.5$ \\
\hline 62.37 & 17.53 & $1968-2001$ & $3.2 \pm 2.8(0.93)$ & $7.0 \pm 1.3$ & $11.3 \pm 0.5$ \\
\hline 64.00 & 20.92 & $1892-2001$ & $6.0 \pm 3.2(0.92)$ & $12.1 \pm 1.3$ & $11.0 \pm 0.5$ \\
\hline 64.92 & 21.23 & $1916-2001$ & $13.4 \pm 3.4(0.93)$ & $11.5 \pm 1.3$ & $11.1 \pm 0.5$ \\
\hline 65.67 & 24.52 & $1920-1997$ & $10.5 \pm 8.3(0.92)$ & $13.6 \pm 1.4$ & $10.4 \pm 0.5$ \\
\hline 65.03 & 25.42 & $1889-1997$ & $10.8 \pm 8.2(0.92)$ & $14.0 \pm 1.4$ & $10.0 \pm 0.5$ \\
\hline 64.67 & 24.42 & $1922-1997$ & $12.0 \pm 7.9(0.92)$ & $16.2 \pm 1.4$ & $9.8 \pm 0.5$ \\
\hline 63.70 & 22.70 & $1914-1997$ & $5.8 \pm 8.2(0.89)$ & $12.5 \pm 1.4$ & $10.2 \pm 0.5$ \\
\hline 63.10 & 21.57 & $1883-1997$ & $4.4 \pm 7.7(0.89)$ & $11.6 \pm 1.3$ & $10.3 \pm 0.5$ \\
\hline 62.33 & 21.22 & $1926-1997$ & $4.5 \pm 6.2(0.93)$ & $10.5 \pm 1.3$ & $9.8 \pm 0.5$ \\
\hline 61.60 & 21.47 & $1910-1997$ & $8.6 \pm 4.2(0.97)$ & $8.7 \pm 1.3$ & $8.9 \pm 0.5$ \\
\hline 61.13 & 21.43 & $1933-1997$ & $7.0 \pm 4.2(0.97)$ & $7.8 \pm 1.3$ & $8.2 \pm 0.5$ \\
\hline 60.43 & 22.10 & $1922-1997$ & $4.0 \pm 4.1(0.97)$ & $4.8 \pm 1.3$ & $6.8 \pm 0.5$ \\
\hline 60.03 & 20.38 & $1924-1997$ & $5.0 \pm 3.5(0.97)$ & $5.9 \pm 1.3$ & $7.1 \pm 0.5$ \\
\hline 59.82 & 22.98 & $1887-1997$ & $7.6 \pm 4.6(0.96)$ & $7.1 \pm 1.4$ & $4.9 \pm 0.5$ \\
\hline 60.15 & 24.97 & $1879-1997$ & $6.0 \pm 4.3(0.97)$ & $6.9 \pm 1.4$ & $4.7 \pm 0.5$ \\
\hline 54.40 & 18.68 & $1951-1999$ & $1.3 \pm 3.7(0.96)$ & $-1.0 \pm 1.3$ & $0.8 \pm 0.5$ \\
\hline 54.80 & 18.42 & $1951-1999$ & $-2.1 \pm 3.8(0.96)$ & $-3.0 \pm 1.4$ & $1.3 \pm 0.5$ \\
\hline 54.58 & 16.87 & $1951-1999$ & $1.4 \pm 4.3(0.95)$ & $0.3 \pm 1.4$ & $2.0 \pm 0.5$ \\
\hline 54.18 & 15.55 & $1951-1999$ & $-4.8 \pm 5.4(0.90)$ & $-0.7 \pm 1.4$ & $2.5 \pm 0.5$ \\
\hline 53.92 & 14.23 & $1811-1999$ & $-7.5 \pm 6.1(0.87)$ & $1.2 \pm 1.6$ & $2.3 \pm 0.5$ \\
\hline
\end{tabular}

\footnotetext{
${ }^{1}$ Individual Altimeter Minus Tide gauge Solution, 1992 - 2001: Estimated vertical motions with formal uncertainties are obtained by differencing tide gauge and TOPEX/POSEIDON altimeter data within $3^{\circ}$ of tide gauges using the same data spans (1992 - 2001). Correlation coefficients between altimeter and tide gauge sea level in parenthesis.

${ }^{2}$ Adjustment Solution, 1992 - 2001: Estimated vertical motions with formal uncertainties obtained using the Gauss-Markov adjustment method employing both data sets spanning only 1992 - 2001. Solution uncertainties are significantly reduced as compared to the above case.

${ }^{3}$ Adjustment Solution, All Data: Estimated vertical motion solutions with uncertainties obtained using the Gauss-Markov adjustment method with employed decadal (1992 - 2001) TOPEX/POSEIDON altimetry and long-term (> 40 years, 1950 - 2001) tide gauge records. Solution uncertainties are further reduced to $0.5 \mathrm{~mm} \mathrm{yr}^{-1}(1 \sigma)$.
} 


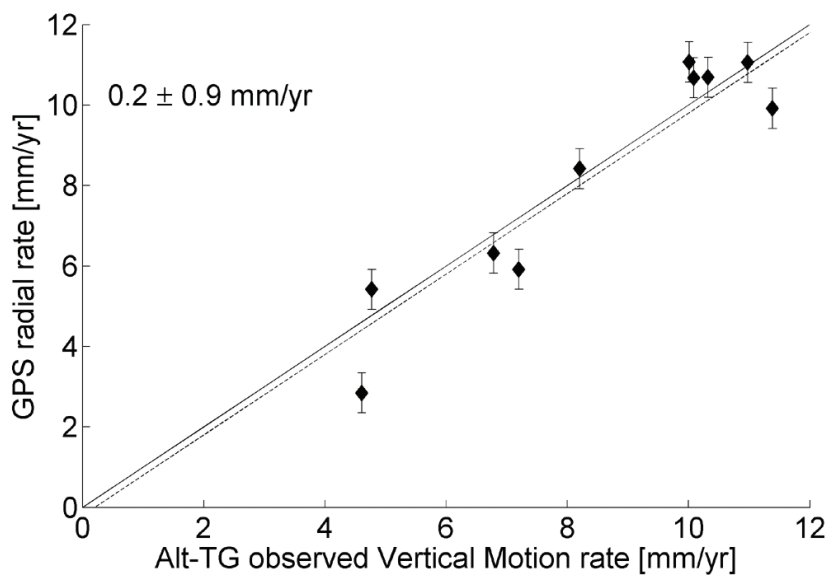

Fig. 4. Comparison of 10 estimated vertical motions with formal standard errors derived from the combination of altimetry and tide gauge records with 10 collocated BIFROST GPS vertical motion estimates (Johansson et al. 2002).

Table 2. Comparison of altimeter-tide gauge determined vertical motion with GIA models (GIA model using ICE-4G deglaciation history (Peltier 2002) and BIFROST GIA model (Milne et al. 2001). The comparison with the BIFROST models has smaller mean differences than with the GIA model using ICE-4G deglaciation history. LT = Lithospheric thickness; UMV = Upper mantle viscosity; LMV = Lower mantle viscosity.

\begin{tabular}{ccc}
\hline GIA & BIFROST Model & BIFROST Model \\
model & LT $=120 \mathrm{~km}$ & LT $=120 \mathrm{~km}$ \\
using & $\mathrm{UMV}=1 \times 10^{21} \mathrm{Pas}$ & $\mathrm{UMV}=1 \times 10^{21} \mathrm{Pas}$ \\
ICE-4G & $\mathrm{LMV}=10 \times 10^{21} \mathrm{Pas}$ & $\mathrm{LMV}=3 \times 10^{21} \mathrm{Pas}$ \\
$3.4 \pm 1.5$ & $1.4 \pm 2.1$ & $1.6 \pm 1.8$ \\
\hline
\end{tabular}

models because of the excellent agreement between computed estimates and GPS solutions (Kuo et al. 2004).

\subsection{Vertical Motions in the Great Lakes}

Absolute vertical motion in the Great Lakes can be derived by following most aspects of the aforementioned procedure. However, in contrast to the averaged absolute vertical motion computed over the Baltic Sea region using TOPEX and tide gauge records, the absolute vertical motion at each water level gauge station is determined individually by averaging TOPEX data over a spatial area (constant radius) and time interval (monthly). A constant radius is chosen based on the correlation coefficients of the absolute and relative lake level changes from TOPEX and water level gauges as well as the number of TOPEX measured points within a constant radius. In the Great Lakes region, $\mathrm{T} / \mathrm{P}$ measurements are mostly located at the center of the lakes, so TOPEX data are averaged over each lake into a time series. Time series of absolute lake level changes from TOPEX are compared with water level gauge records, and found to be highly correlated with correlation coefficients $>0.95$. Similarly, the correlation coefficients between individual water level gauge records are larger than 0.9 except around Lake Erie $(>0.8)$. Based on the knowledge of vertical motion around the Great Lakes, which could be largely due to GIA, a linear model is implemented to describe the motion.

The uncertainties of the estimates derived from the adjustment algorithm are significantly reduced to less than $0.5 \mathrm{~mm} \mathrm{yr}^{-1}$ (Column 4 in Table 3), while the traditional method results in uncertainties of $0.6-1.6 \mathrm{~mm} \mathrm{yr}^{-1}$ (Column 3 in Table 3). Figure 5 illustrates the estimates of geocentric vertical motion averaged in each lake compared with a GIA model prediction using the ICE-4G model (Peltier 2002), the ICE-3G GIA model (Tushingham and Peltier 1991), and the water level gauge relative vertical motion solution (Mainville and Craymer 2005). Results show excellent agreement except for the ICE-4G GIA model, which exhibits smaller amplitudes. Figure 2 indicates the discrepancy at each gauge station between the estimates, the GIA models with the ICE-4G and the ICE-3G deglaciation histories, GPS velocities (Snay et al. 2002; M. Cline and R. Snay, National Geodetic Survey solution, personal communications, 2004), and water level gauge analysis. Excluding GPS, the pattern of vertical motion is nearly uniform and exhibits uplift in Lake Superior, Lake Huron, Lake Ontario, and the upper part of Lake Michigan and Lake Erie, and subsidence in the lower part of Lake Michigan and Lake Erie. The ICE-3G GIA model agrees better with our estimates than ICE-4G.

The GIA model using the ICE-3G and the ICE-4G GIA model show insignificant mean differences at $-0.2 \pm$ $0.6 \mathrm{~mm} \mathrm{yr}^{-1}$ and $0.1 \pm 0.9 \mathrm{~mm} \mathrm{yr}^{-1}$ respectively when compared with our estimates (Table 4). In addition, vertical motion derived from water level gauge analysis is consistent with our estimates with a mean difference of $-0.1 \pm$ $0.5 \mathrm{~mm} \mathrm{yr}^{-1}$, but with a relatively large discrepancy in the northern part of Lake Huron. The inconsistency may result from the different selection of the unknown absolute vertical solutions; Mainville and Craymer (2005) consider that the means of the vertical motions derived from water gauges and the ICE-3G GIA model have to be the same while the combination of TOPEX and tide gauge data provides the absolute vertical motions directly. The new technique has the potential to further constrain Earth parameters of GIA models in the Great Lakes region.

\subsection{Vertical Motion in Alaska}

In certain regions, absolute vertical motion could include linear or nonlinear variations or a combination of both. The quadratic deformation, which is a nonlinear term, could be caused by the co- or postseismic deformation, like 
Table 3. Estimated vertical motions determined using decadal TOPEX/POSEIDON altimetry and long-term water level gauge data around the Great Lakes.

\begin{tabular}{|c|c|c|c|}
\hline $\begin{array}{l}\text { Latitude } \\
\text { (Degree) }\end{array}$ & $\begin{array}{l}\text { Longitude } \\
\text { (Degree) }\end{array}$ & Altimeter $\underset{(\mathrm{mm} / \mathrm{yr})}{\operatorname{minus} \mathrm{TG}}$ solution ${ }^{1}$ & $\begin{array}{c}\text { Adjustment solution }{ }^{2} \\
(\mathrm{~mm} / \mathrm{yr})\end{array}$ \\
\hline \multicolumn{4}{|c|}{ Lake Erie } \\
\hline 281.11 & 42.88 & $2.0 \pm 1.6$ & $0.4 \pm 0.4$ \\
\hline 279.93 & 42.15 & $2.7 \pm 1.2$ & $-0.5 \pm 0.4$ \\
\hline 278.72 & 41.75 & $-1.8 \pm 0.8$ & $-1.5 \pm 0.4$ \\
\hline 278.37 & 41.54 & $-1.0 \pm 0.8$ & $0.1 \pm 0.4$ \\
\hline 277.27 & 41.55 & $0.0 \pm 1.4$ & $0.1 \pm 0.4$ \\
\hline 276.53 & 41.69 & $-2.9 \pm 1.6$ & $-0.3 \pm 0.4$ \\
\hline 276.74 & 41.96 & $-1.5 \pm 1.3$ & $-0.1 \pm 0.4$ \\
\hline 276.88 & 42.15 & $-0.9 \pm 1.3$ & $0.2 \pm 0.4$ \\
\hline 276.88 & 42.05 & $-2.1 \pm 1.1$ & $-1.0 \pm 0.4$ \\
\hline 277.27 & 42.03 & $-0.6 \pm 1.0$ & $-0.3 \pm 0.4$ \\
\hline 278.08 & 42.27 & $0.9 \pm 0.8$ & $-0.1 \pm 0.4$ \\
\hline 278.78 & 42.67 & $-0.1 \pm 0.8$ & $-0.3 \pm 0.4$ \\
\hline 279.80 & 42.78 & $1.0 \pm 1.1$ & $0.3 \pm 0.4$ \\
\hline 280.75 & 42.87 & $1.5 \pm 1.4$ & $0.2 \pm 0.4$ \\
\hline \multicolumn{4}{|c|}{ Lake Huron } \\
\hline 277.36 & 43.85 & $1.5 \pm 0.7$ & $1.2 \pm 0.3$ \\
\hline 276.15 & 43.64 & $-1.2 \pm 1.1$ & $0.6 \pm 0.3$ \\
\hline 275.28 & 45.78 & $2.6 \pm 0.7$ & $2.1 \pm 0.3$ \\
\hline 276.10 & 45.99 & $2.5 \pm 0.7$ & $2.7 \pm 0.3$ \\
\hline 276.45 & 46.25 & $3.7 \pm 0.7$ & $3.3 \pm 0.3$ \\
\hline 278.07 & 45.98 & $3.2 \pm 0.7$ & $3.1 \pm 0.3$ \\
\hline 279.97 & 45.33 & $3.1 \pm 0.7$ & $3.1 \pm 0.3$ \\
\hline 279.74 & 44.50 & $2.1 \pm 0.7$ & $2.0 \pm 0.3$ \\
\hline 278.33 & 45.27 & $1.9 \pm 0.6$ & $2.8 \pm 0.3$ \\
\hline 278.27 & 43.75 & $1.3 \pm 0.7$ & $0.4 \pm 0.3$ \\
\hline 277.51 & 43.14 & $0.9 \pm 0.9$ & $0.8 \pm 0.3$ \\
\hline 276.71 & 44.66 & $1.3 \pm 0.8$ & $1.7 \pm 0.3$ \\
\hline
\end{tabular}




\section{Lake Michigan}

\begin{tabular}{|c|c|c|c|}
\hline 273.56 & 43.95 & $0.6 \pm 0.9$ & $-1.2 \pm 0.5$ \\
\hline 272.46 & 41.73 & $-0.7 \pm 1.0$ & $-0.6 \pm 0.5$ \\
\hline 272.11 & 43.00 & $-0.8 \pm 0.9$ & $-1.3 \pm 0.5$ \\
\hline 272.69 & 44.80 & $-1.5 \pm 0.9$ & $-0.2 \pm 0.5$ \\
\hline 271.99 & 44.54 & $-2.3 \pm 1.0$ & $-1.0 \pm 0.5$ \\
\hline 274.13 & 45.97 & $1.0 \pm 0.9$ & $1.0 \pm 0.5$ \\
\hline 273.80 & 42.77 & $-0.2 \pm 1.3$ & $-0.7 \pm 0.5$ \\
\hline 272.50 & 44.46 & $-0.6 \pm 1.2$ & $-0.4 \pm 0.5$ \\
\hline \multicolumn{4}{|c|}{ Lake Ontario } \\
\hline 283.66 & 44.13 & $1.3 \pm 0.7$ & $1.5 \pm 0.3$ \\
\hline 283.49 & 43.46 & $1.1 \pm 0.7$ & $1.3 \pm 0.3$ \\
\hline 282.37 & 43.27 & $1.1 \pm 0.7$ & $1.2 \pm 0.3$ \\
\hline 280.78 & 43.23 & $0.8 \pm 0.7$ & $0.4 \pm 0.3$ \\
\hline 280.23 & 43.33 & $0.5 \pm 0.8$ & $-0.1 \pm 0.3$ \\
\hline 280.62 & 43.63 & $-0.1 \pm 0.7$ & $1.0 \pm 0.3$ \\
\hline 281.83 & 43.95 & $2.0 \pm 0.7$ & $1.3 \pm 0.3$ \\
\hline 283.48 & 44.22 & $1.6 \pm 0.8$ & $1.7 \pm 0.3$ \\
\hline \multicolumn{4}{|c|}{ Lake Superior } \\
\hline 275.37 & 46.49 & $3.4 \pm 0.6$ & $2.5 \pm 0.4$ \\
\hline 272.62 & 46.55 & $0.7 \pm 0.5$ & $1.3 \pm 0.4$ \\
\hline 270.68 & 46.88 & $0.7 \pm 0.5$ & $0.1 \pm 0.4$ \\
\hline 267.91 & 46.78 & $-1.7 \pm 0.7$ & $-0.7 \pm 0.4$ \\
\hline 269.66 & 47.75 & $1.3 \pm 0.5$ & $1.3 \pm 0.4$ \\
\hline 270.78 & 48.42 & $0.8 \pm 0.5$ & $2.1 \pm 0.4$ \\
\hline 272.48 & 48.83 & $4.7 \pm 0.5$ & $4.2 \pm 0.4$ \\
\hline 275.10 & 47.97 & $4.2 \pm 0.6$ & $4.3 \pm 0.4$ \\
\hline 275.42 & 46.53 & $3.8 \pm 0.6$ & $2.2 \pm 0.4$ \\
\hline
\end{tabular}

\footnotetext{
${ }^{1}$ Altimeter Minus Water Level Gauge Solution, 1992 - 2002: Vertical motion solutions with corresponding formal uncertainty are obtained differencing water level gauge and TOPEX/POSEIDON altimeter data within $3^{\circ}$ of water level gauges using same data spans (1992 - 2002).

${ }^{2}$ Adjustment Solution, All Data: Vertical motion solutions with formal uncertainties obtained using the Gauss-Markov adjustment method with stochastic constraints and using decadal (1992 - 2002) TOPEX/POSEIDON altimetry and long-term water level gauge data.
} 


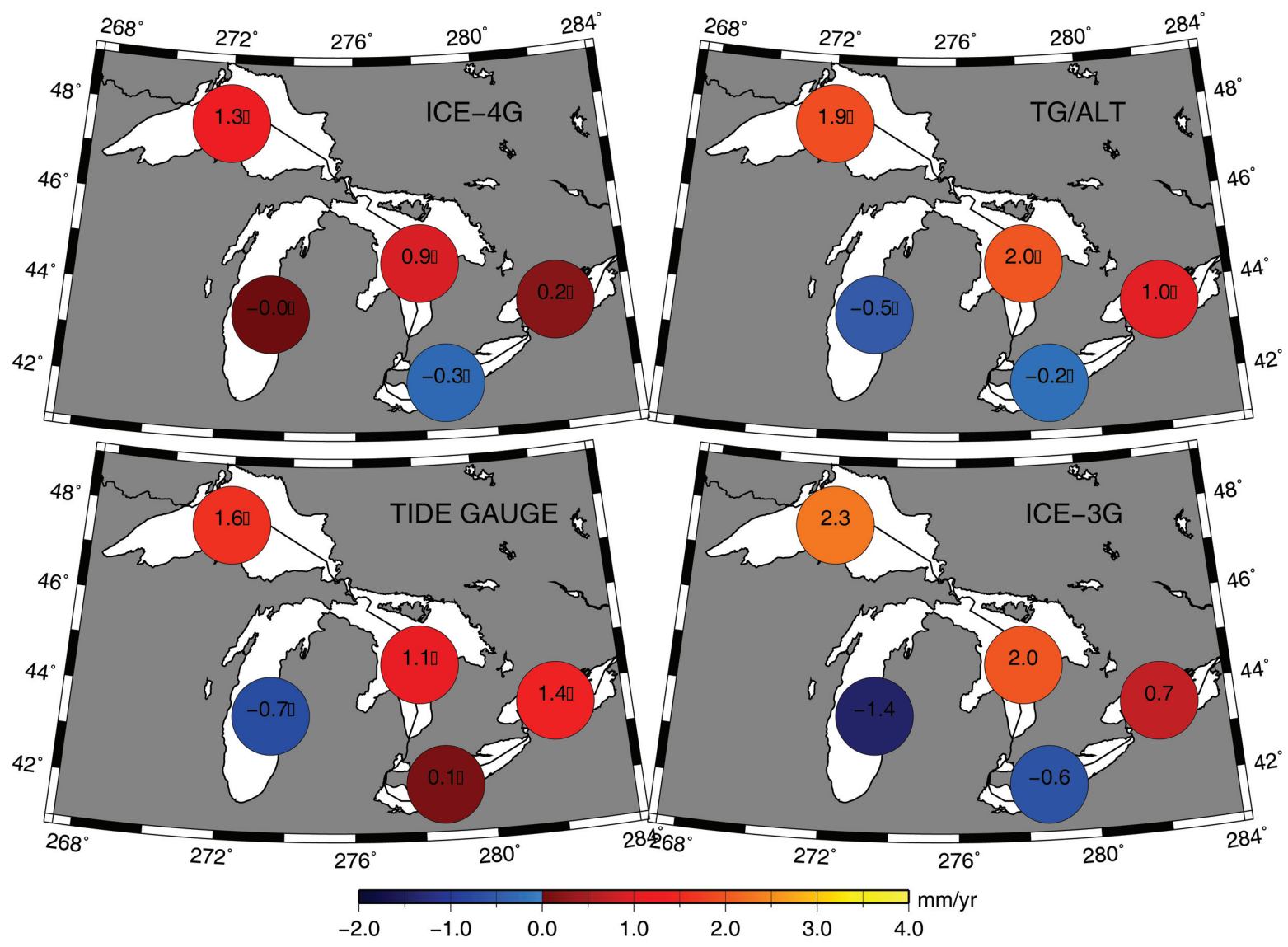

Fig. 5. Comparison of averaged estimated absolute vertical motions (top-right), ICE-4G GIA model (top-left) (Peltier 2002), ICE-3G GIA model (bottom-right) (Tushingham and Peltier 1991), and water level gauge analysis (bottom-left) (Mainville and Craymer 2005) around each of the lakes.

Table 4. Mean differences between crustal vertical motion estimates of GIA models and TG/Altimetry combination. UMV/LMV in $10^{21}$ Pas, LT in $\mathrm{km}$. M2 includes the geoid change due to GIA. LT = Lithospheric thickness; UMV = Upper mantle viscosity; LMV = Lower mantle viscosity. Mainville and Craymer (2005) analyzed only water level gauge data for relative vertical motion with respect to ICE-3G GIA model.

\begin{tabular}{cccc}
\hline$\#$ & Observation/Model & Mean of Difference $\left(\mathbf{m m} \mathbf{y r}^{-1}\right)$ & STD. $\left(\mathbf{m m} \mathbf{~ y r}^{-1}\right)$ \\
\hline M1 & GIA using ICE-4G LT $=120 \mathrm{UMV}=.5 \mathrm{LMV}=3$ & 0.1 & 0.9 \\
M2 & GIA using ICE-4G LT $=120 \mathrm{UMV}=.5 \mathrm{LMV}=3$ & -0.1 & 0.9 \\
M3 & GIA using ICE-3G LT $=120 \mathrm{UMV}=1 \mathrm{LMV}=2$ & -0.2 & 0.6 \\
M4 & Mainville and Craymer (2005) analysis & -0.1 & 0.5 \\
\hline
\end{tabular}

in the Alaskan coastal region (Larsen et al. 2003). Analyzing various types of deformation resulting in vertical motions is necessary for improving the accuracy of the estimates. A separation of secular, periodic, instantaneous, and nonlinear motions would be particularly beneficial. In order to consider geocentric vertical motions as a quadratic model, the difference of sea level change at each epoch could be used as observations in the adjustment instead of the rates of change in Eqs. (2) and (3). The difference of altimeter data and corresponding tide gauge records at each epoch, $g_{i, t}\left(\lambda_{i}, \varphi_{i}\right)-S_{i, t}\left(\lambda_{i}, \varphi_{i}\right)$, can be written according to Eq. (2) as:

$$
\begin{aligned}
u_{i, t}\left(\lambda_{i}, \varphi_{i}\right) & =g_{i, t}\left(\lambda_{i}, \varphi_{i}\right)-S_{i, t}\left(\lambda_{i}, \varphi_{i}\right) \\
& =a_{i}+b_{i}\left(t-t_{0}\right)+c_{i}\left(t-t_{0}\right)^{2}
\end{aligned}
$$


where $g_{i, t}$ and $S_{i, t}$ are relative and absolute sea level changes measured by altimeters and corresponding tide gauge, $i$, at epoch $t, t_{0}$ is the reference time set as 1990 in this study; $a, b$, and $c$ are the coefficients of the constant, the linear change rate, and the quadratic term. The criterion for selecting a tide gauge station depends on the value of the correlation coefficient of TOPEX data and tide gauge records covering the same time span which should be greater than 0.8 for high correlation.

The difference between two adjacent tide gauge records $(i$ and $j)$ at each epoch, $-S_{i, t}\left(\lambda_{i}, \varphi_{i}\right)+S_{j, t}\left(\lambda_{j}, \varphi_{j}\right)$ derived from Eq. (3) is:

$$
\begin{aligned}
r u_{i j, t} & =-S_{i, t}\left(\lambda_{i}, \varphi_{i}\right)+S_{j, t}\left(\lambda_{j}, \varphi_{j}\right) \\
& =u_{i, t}-u_{j, t} \\
& =a_{i}+b_{i}\left(t-t_{0}\right)+c_{i}\left(t-t_{0}\right)^{2}-a_{j}-b_{j}\left(t-t_{0}\right)-c_{j}\left(t-t_{0}\right)^{2}
\end{aligned}
$$

The same correlation coefficient criterion $(>0.8)$ was implemented for two adjacent tide gauge records covering the same time span. By substituting, $g_{i, t}\left(\lambda_{i}, \varphi_{i}\right)-S_{i, t}\left(\lambda_{i}, \varphi_{i}\right)$ and - $S_{i, t}\left(\lambda_{i}, \varphi_{i}\right)+S_{j, t}\left(\lambda_{j}, \varphi_{j}\right)$ from Eqs. (9) and (10) into Eq. (4) as observations, we can optimally solve for the unknown parameters, $a, b$, and $c$ via Eqs. (6) and (7). The formal standard errors of change rates are $1.5-2.5 \mathrm{~mm} \mathrm{yr}^{-1}$ obtained by fitting the same time span data of the absolute and relative vertical motions in Eqs. (9) and (10). This implies that $u_{i j}$ and $r u_{i j . t}$ could be considered to have equivalent accuracy even though the observations consist of different types of data (differences of TOPEX with tide gauge data and differences between various tide gauge records, respectively). Therefore, the diagonal elements of $\Sigma_{0}$ and $\Sigma_{1}$ are set equal to $\sigma_{v}^{2}$, and $\sigma_{v}$ is equal to $10 \mathrm{~mm}$ to represent the error of tide gauge records. The off-diagonal elements of $\Sigma_{0}$ and $\Sigma_{2}$ are set equal to $\sigma_{v}^{2} \times 0.3$, which means the correlation coefficient of the computed absolute or relative vertical motions is taken empirically as 0.3 when the absolute or relative vertical motions are computed using the same tide gauge records.

Larsen et al. (2003) have performed a comprehensive analysis of vertical motions in Alaska. The geocentric vertical motions are calculated in the present adjustment analysis by adopting an assumed type of vertical motions. The tide gauge stations are separated into two regions (see Fig. 3). Region I contains Yakutat, Sitka, Skagway, Juneau, Ketchikan, Prince Rupert, and Queen Charlotte City (triangles in Fig. 3). Geocentric vertical motions in this region are represented by a linear model except station Yakutat. Region II includes Sand Point, Kodiak, Anchorage, Nikiski, Seldovia, Seward, Valdez, and Cordova (circles in Fig. 3). Geocentric vertical motions of most stations in this region are modeled by a quadratic polynomial primarily because of the anticipated effect of the co- or postseismic crustal deformation following the 1964 Great Alaskan earthquake.

Table 5 shows the estimated coefficients of geocentric vertical motions. In region I, Yakutat, Sitka, Skagway, and Juneau stations have large uplift rates that may be caused by regional GIA or regional tectonic stress (Barnes 1984). The global GIA model using the ICE-4G ice history in region I suggests an uplift rate of only $<1 \mathrm{~mm} \mathrm{yr}^{-1}$, which is significantly smaller than the estimated vertical motion. The underestimation of the GIA model in this region may be due to limited knowledge of ice loading history (e.g., Tushingham and Peltier 1991). The discrepancy could also be caused by solid Earth elastic loading effect due to present-day glacier melting, which is unaccounted for here. Therefore, our estimates may provide constraints on the deglaciation history in region I, and present-day glacier melt. In addition to adopting the quadratic model, the linear model has been tested in region II. The F- ratio of the linear and quadratic models used for model analysis is defined by (Zhao et al. 1995):

$F=\frac{\left(S S R_{2}-S S R_{1}\right) /\left(D F_{2}-D F_{1}\right)}{S S R_{1} / D F_{1}}$

where $S S R$ is the sum of the squared residuals and $D F$ is the number of degrees of freedom (number of data points minus number of unknown parameters). The subscripts 1 and 2 refer to models without and with the extra parameters, respectively. According to Eq. (11), F equals 20.5, so the quadratic model passes the F-test at the $0.1 \%$ level (F-ratio > 10.8) (Beyer 1991). Anchorage, Seward, Valdez, and Cordova stations exhibit a similar quadratic form in uplift rates. Kodiak and Nikiski show the negative values of the quadratic terms, however there is a large data gap in the records for the Nikiski station, which implies a less reliable estimate. Table 6 shows a comparison of the absolute vertical motions derived from three solutions, namely, (i) altimeter-tide gauges, (ii) tide gauges only (Larsen et al. 2003), and (iii) GPS vertical velocity solutions at four tide gauge stations [data from the latter provided by Larsen et al. (2005)].

Figure 6 shows a comparison of the absolute vertical motions derived from altimeter-tide gauges (this study) and relative vertical motion only using tide gauges at 15 Alaskan sites in the year 2000 (Table 6) (Larsen et al. 2003). The rate of absolute vertical motion at Yakutat observed by altimeter and tide gauges in 2000 is $10.5 \mathrm{~mm} \mathrm{yr}^{-1}$ from the estimation of the quadratic model; however, there is an unknown shift of tide gauge data in January 1992 (Larsen et al. 2003). If this shift is corrected, the vertical motion rate increases from 10.5 to $13.5 \mathrm{~mm} \mathrm{yr}^{-1}$. The mean value of the differences between solutions from Larsen et al. (2003) and this study in region I and region II are $-1.0 \pm 0.7$ and $-2.7 \pm$ $4.2 \mathrm{~mm} \mathrm{yr}^{-1}$, respectively. Although the results are consistent within the uncertainty level in region I, significant dis- 
crepancies exists in region II. By eliminating two stations, Nikiski and Kodiak, the mean difference between solutions increases from $-2.7 \pm 4.2$ to $-4.8 \pm 1.2 \mathrm{~mm} \mathrm{yr}^{-1}$ and the standard deviation decreases. This disagreement may be caused by introducing different absolute sea level variations. Possible explanations may also involve the use of altimetric sea level change rates employed by this study, whereas Larsen et al. (2003) used almost an equal rate of sea level change across the region. Figure 7 provides a geographical comparison of the altimeter-tide gauge derived geocentric vertical motions and GPS solutions. The mean difference in this region is $0.65 \pm 0.85 \mathrm{~mm} \mathrm{yr}^{-1}$. In order to adopt this approach to the open ocean, it is necessary to obtain absolute sea level variations at different gauge stations, which may be known or could be modeled with sufficient accuracy.

\section{CONCLUSIONS}

A new robust technique to estimate absolute vertical motion using both satellite altimetry and tide gauge records in Fennoscandia, Alaskan coast, and the Great Lakes is pre- sented. The estimated absolute vertical motions at 25 tide gauge locations around the Baltic Sea have an uncertainty of $0.5 \mathrm{~mm} \mathrm{yr}^{-1}(1 \sigma)$, which is significantly smaller than the traditional approach at $1-2 \mathrm{~mm} \mathrm{yr}^{-1}$ (e.g., Nerem and Mitchum 2002). This difference can be attributed to the use of an adjustment technique which optimally combines short-term altimetry and long-term tide gauge records. The close agreement between the estimates computed herein and GPS solutions suggests the potential for improved constraints to GIA modeling using results from this study.

Around the Great Lakes, the uncertainties obtained from the traditional method are $0.6-1.6 \mathrm{~mm} \mathrm{yr}^{-1}$ (Nerem and Mitchum 2002). By applying the adjustment approach described herein, the uncertainties have been reduced to $<0.5 \mathrm{~mm} \mathrm{yr}^{-1}$. In Lakes Michigan and Erie, subsidence prevails, whereas land uplift dominates in Lakes Ontario, Superior, and Huron. The estimated vertical motion agrees well with vertical motion determined from the tide-gauge-only analysis (Mainville and Craymer 2005) with a difference of $-0.1 \pm 0.5 \mathrm{~mm} \mathrm{yr}^{-1}$. However, at present the estimates have a large discrepancy with GPS vertical solutions. The disagree-

Table 5. Estimated coefficients of the absolute vertical motions. Coefficients $b$ and $c$ are defined in Eqs. (9) and (10).

\begin{tabular}{|c|c|c|}
\hline Tide gauge & Linear model & Quadratic model \\
\hline Region I (1950 - 2002) & $\left(\mathbf{m m} \mathbf{y r}^{-1}\right)$ & $\mathrm{b}\left(\mathrm{mm} \mathrm{yr} \mathbf{r}^{-1}\right) ; \mathrm{c}\left(\mathrm{mm} \mathrm{yr}^{-2}\right)$ \\
\hline Yakutat & - & $8.6 \pm 1.2 ; 0.09 \pm 0.01$ \\
\hline Sitka & $1.4 \pm 1.3$ & - \\
\hline Skagway & $15.8 \pm 1.3$ & - \\
\hline Juneau & $11.9 \pm 1.2$ & - \\
\hline Ketchikan & $-0.3 \pm 1.3$ & - \\
\hline Prince Rupert & $-1.1 \pm 1.3$ & - \\
\hline Queen Charlotte City & $-0.5 \pm 1.3$ & - \\
\hline Region II (1973 - 2002) & $\left(\mathbf{m m} \mathbf{y r}^{-1}\right)$ & $\mathrm{b}\left(\mathrm{mm} \mathrm{yr}^{-1}\right) ; \mathrm{c}\left(\mathrm{mm} \mathrm{yr^{-2 } )}\right.$ \\
\hline Sand Point & $-4.5 \pm 1.5$ & - \\
\hline Kodiak & - & $7.7 \pm 1.7 ;-0.07 \pm 0.72$ \\
\hline Anchorage & - & $-3.0 \pm 1.6 ; 0.35 \pm 0.60$ \\
\hline Nikiski & - & $7.5 \pm 1.6 ;-0.04 \pm 0.81$ \\
\hline Seldovia & $6.8 \pm 1.6$ & - \\
\hline Seward & - & $-1.0 \pm 1.5 ; 0.28 \pm 0.41$ \\
\hline Valdez & - & $-1.2 \pm 1.5 ; \quad 0.50 \pm 0.52$ \\
\hline Cordova & - & $-7.5 \pm 1.5 ; 0.27 \pm 0.44$ \\
\hline
\end{tabular}


Table 6. Comparison of the absolute vertical motions derived from TOPEX/POSEIDON and tide gauge records, GPS vertical velocities, and tide gauge records only (Larsen et al. 2003). Uplift rates at the year 2000.

\begin{tabular}{|c|c|c|c|}
\hline Tide gauge & $\begin{array}{l}\text { TOPEX Altimetry \& } \\
\text { Tide Gauge }\left(\mathbf{m m} \mathbf{y r}^{-1}\right)\end{array}$ & GPS $\left(\mathbf{m m ~ y r} \mathbf{r}^{-1}\right)$ & $\begin{array}{c}\text { Tide Gauges }\left(\mathrm{mm} \mathrm{yr}^{-1}\right) \\
\text { Larsen et al. }(2003)\end{array}$ \\
\hline Yakutat & 13.5 & $13 \sim 14$ & 13.7 \\
\hline Sitka & 1.4 & $0 \sim-1$ & 3.0 \\
\hline Skagway & 15.8 & $15 \sim 16$ & 17.1 \\
\hline Juneau & 11.9 & $11 \sim 12$ & 13.6 \\
\hline Ketchikan & -0.3 & & 0.0 \\
\hline Prince Rupert & -1.1 & & -0.7 \\
\hline Queen Charlotte City & -0.5 & & 1.0 \\
\hline Sand Point & -4.5 & & 0.1 \\
\hline Kodiak & 6.2 & & 5.4 \\
\hline Anchorage & 4.4 & & 10.4 \\
\hline Nikiski & 6.7 & & 0.5 \\
\hline Seldovia & 6.8 & & 9.6 \\
\hline Seward & 4.9 & & 10.4 \\
\hline Valdez & 8.8 & & 12.9 \\
\hline Cordova & -1.8 & & 3.8 \\
\hline
\end{tabular}

ment may be caused by unstable GPS solutions which are amalgamated from different sources and in general do not agree well due to the use of different reference frames and the solutions used are based on absolute vertical solutions (e.g., Snay et al. 2002). On the other hand, the BIFORST GPS vertical solution used a primarily kinematic solution approach (Johansson et al. 2002).

In the Alaskan coastal region, the uncertainties of vertical motion estimates are in excess of $1 \mathrm{~mm} \mathrm{yr}^{-1}$ as a consequence of the open ocean. In open oceans, the assumption that the rates of absolute sea level variations are the same at nearby gauges is not necessarily sufficient. Nonetheless, the uncertainties of our estimates are reduced significantly compared to the traditional method with an averaged standard deviation of $3.2 \mathrm{~mm} \mathrm{yr}^{-1}$. In addition there is good agreement with these estimates and solutions from GPS and those of Larsen et al. (2003). These values are not consistent with the GIA models because of the limited knowledge of the ice loading history in Alaska (Larsen et al. 2005), as well as the unaccounted effects of elastic loading due to present-day glacier melt. This approach has the potential to be applied in open oceans, to deal with nonlinear vertical motions, to contribute to constraints in GIA models, as well to study the ice loading history and Earth rheology.

The next step to improve the vertical motion determination is to lengthen the time span of altimeter data, which should produce a commensurate improvement in accuracy for the geocentric vertical motion estimates. Extension of the T/P data span using JASON and linking with GEOSAT (1984 - 1990), and other altimetry data (e.g., GFO, ENVISAT, ERS-1/-2) should lead to improved vertical motion estimates. Further improvements to the adjustment algorithm would involve introducing local sea level change rates from general ocean circulation models, such as the ECCO model (Fukumori et al. 1999). This would eliminate the current assumption that adjacent tide gauge stations measure identical sea level variations. A detailed analysis of the correlations between the tide gauge data and altimeter data will be conducted to enhance the error model. Waveform retracking techniques could also be employed to provide additional and more reliable altimeter sea surface height data closer to tide gauge stations (Deng and Featherstone 2006). Overall, the improvement of vertical motion estimates at global tide gauge sites caused by GIA and other phenomena, should improve the accuracy of global sea level change measurements. 


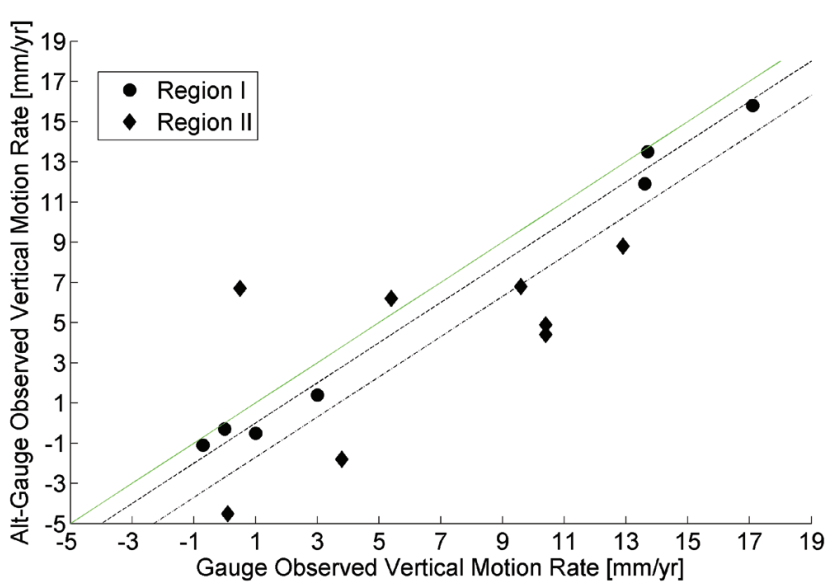

Fig. 6. Estimated absolute vertical motions derived from the combination of altimeter and tide gauge records and from tide gauge records only (Larsen et al. 2003) in the year 2000. Circles indicate tide gauge stations in region I and diamonds indicate tide gauges in region II. The dashed and dash-dot lines show the mean differences of two observations in region I and region II respectively compared to the solid line.

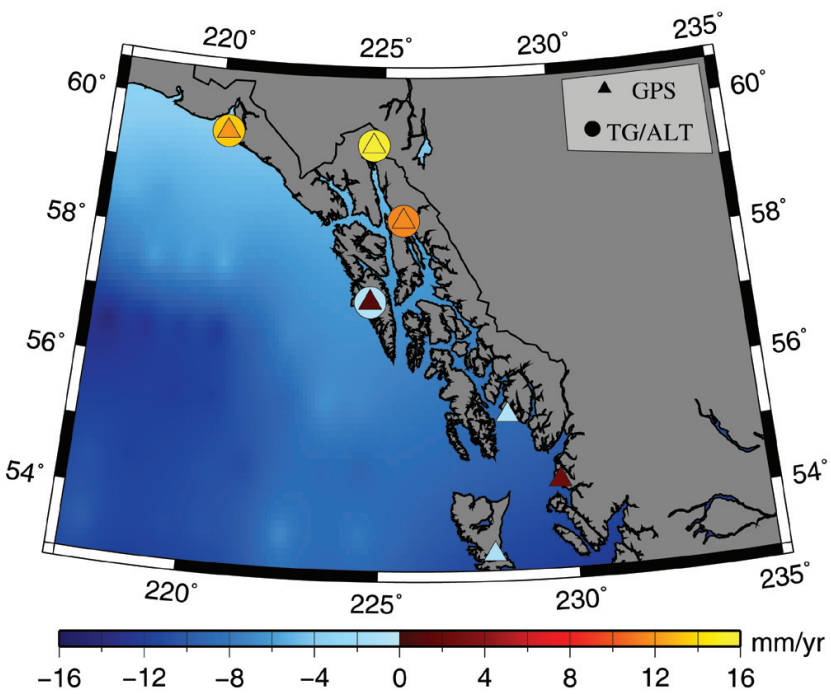

Fig. 7. Geographical comparison of altimeter-tide gauge derived absolute vertical motions (triangles) and GPS solutions (circles). The background is altimetric sea level changes derived from Geosat, ERS-1, ERS-2, and TOPEX/POSEIDON from 1985 to 2003 with a data gap for $1988-1991$.

Acknowledgements TOPEX/POSEIDON data are provided by Physical Oceanography Distributed Active Archive Center (PO.DAAC). Tide gauge data are provided by NOAA (USA), MEDS (Canada), and PSMSL (UK). We thank Anny Cazenave and an anonymous reviewer for their constructive comments. This research is supported by the Landmark Project Grant for NCKU's Top-University Project, New Star Program from College of Engneering in NCKU, NOAA/NEDIS (NA06NES40007), and NASA's Interdisciplinary Science Program (NNG04GN19G).

\section{REFERENCES}

Barnes, D. F., 1984: No measurable gravity change at Glacier Bay regional uplift area. US Geol. Surv. Circ., 939, 88-90.

Beyer, W. H., 1991: CRC Standard Mathematical Tables and Formulae, CRC press, Boca Raton, Fla.

Caccamise, D. J., II, M. A. Merrifield, M. Bevis, J. Foster, Y. L. Firing, M. S. Schenewerk, F. W. Taylor, and D. A. Thomas, 2005: Sea level rise at Honolulu and Hilo, Hawaii: GPS estimates of differential land motion. Geophys. Res. Lett., 32, L03607, doi: 10.1029/ 2004GL021380.

Cazenave, A., K. Dominh, F. Ponchaut, L. Soudarin, J. F. Cretaux, and C. Le Provost, 1999: Sea level changes from Topex-Poseidon altimetry and tide gauges, and vertical crustal motions from DORIS. Geophys. Res. Lett., 26, 2077-2080.

Chambers, D. P., S. A. Hayer, J. C. Ries, and T. J. Urban, 2003: New TOPEX sea state bias models and their effect on global mean sea level. J. Geophys. Res., 108, 3305-3311.

Cheng, K. C., C. Y. Kuo, C. K. Shum, X. Niu, R. Li, and K. W. Bedford, 2008: Accurate linking of Lake Erie water level with shoreline datum using GPS buoy and satellite altimetry. Terr. Atmos. Ocean. Sci., 19, 53-62, doi: 10.3319/TAO.2008.19.1-2.53(SA).

Deng, X., W. E. Featherstone, 2006: A coastal retracking system for satellite radar altimeter waveforms: Application to ERS-2 around Australia. J. Geophys. Res., 111, C06012, doi: 10.1029/2005JC003039.

Douglas, B., 2001: Sea level change in the era of the recording tide gauge. In: Douglas, B., M. Kearney, and S. Leatherman (Eds.), Sea Level Rise: History and Consequences, Academic Press, 37-64.

Fukumori, I., R. Raghunath, L. L. Fu, and Y. Chao, 1999: Assimilation of TOPEX/POSEIDON altimeter data into a global ocean circulation model: How good are the results? J. Geophys. Res., 104, 25647-25666.

Hofmann-Wellenhof, B., and H. Moritz, 2006: Physical Geodesy, $2^{\text {nd }}$ corrected edition, Springer-Verlag Wien, New York.

Johansson, J., J. Davis, H. Scherneck, G. Milne, M. Vermeer, J. Mitrovica, R. Bennett, B. Jonsson, G. Elgered, P. Elósegui, H. Koivula, M. Poutanen, B. Rönnäng, and I. Shapiro, 2002: Continuous GPS measurements of postglacial adjustment in Fennoscandia 1. Geodetic Results. J. Geophys. Res., 107, doi: 10.1029/2001JB000400.

Koch, K., 1999: Parameter Estimation and Hypothesis Testing in Linear Models, $2^{\text {nd }}$ edition, Springer.

Kruizinga, G. L. H, 1997: Validation and applications satellite radar altimetry. Ph.D. Thesis, University of Texas at Austin, Austin, Texas, USA, 309 pp.

Kuo, C. Y., C. K. Shum, A. Braun, and J. X. Mitrovica, 2004: 
Vertical crustal motion determined by satellite altimetry and tide gauge data in Fennoscandia. Geophys. Res. Lett., 31, L01608, doi: 10.1029/2003GL019106.

Larsen, C., K. Echelmeyer, J. Freymueller, and R. Motyka, 2003: Tide gauge records of uplift along the northern Pacific-North America plate boundary, 1937 to 2001. J. Geophys. Res., 108, 2216, doi: 10.1029/ 2001JB001685.

Larsen, C., R. Motyka, J. Freymueller, K. Echelmeyer, and E. Ivins, 2005: Rapid viscoelastic uplift in southeast Alaska caused by post-Little Ice Age glacial retreat. Earth Planet. Sci. Lett., 237, 548-560.

Lin, J., 2000: Correction of tide gauge measurements to absolute sea level by vertical motion solutions. Master Thesis, The Ohio State University, Columbus, Ohio, USA, 66 pp.

Mainville, A., and M. Craymer, 2005: Present-day tilting of the Great Lakes region based on water level gauges. Geol. Soc. Am. Bull., 117, doi: 10.1130/B25392.1.

Mäkinen, J., and V. Saaranen, 1998: Determination of postglacial land uplift from the three precise levellings in Finland. J. Geodesy, 72, 516-529.

Milne, G., J. Davis, J. Mitrovica, H. Scherneck, J. Johansson, M. Poutanen, and H. Koivula, 2001: Space-geodetic constraints on glacial isostatic adjustment in Fennoscandia. Science, 291, 2381-2385.

Nerem, R., and G. Mitchum, 2002: Estimates of vertical crustal motion derived from differences of TOPEX/POSEIDON and tide gauge sea level measurements. Geophys. Res. Lett., 29, 1934, doi: 10.1029/2002GL015037.
Pagiatakis, S. D., and P. Salib, 2003: Historical relative gravity observations and the time rate of change of gravity due topostglacial rebound and other tectonic movements in Canada. J. Geophys. Res., 108, 2406, doi: 10.1029/2001JB001676.

Peltier, W., 2002: Global glacial isostatic adjustment: palaeogeodetic and space-geodetic tests of the ICE-4G (VM2) model. J. Quat. Sci., 17, 491-510.

Shum, C., C. Y. Kuo, and J. Mitrovica, 2002: Glacial isostatic adjustment in the Great Lakes region inferred by tide gauges and satellite altimetry. Spring AGU Meeting, Washington DC.

Snay, R., M. Chin, D. Coner, T. Soler, C. Zervas, J. Oyler, M. Craymer, S. I. Gutman, C. K. Shum, K. C. Cheng, and C. Y. Kuo, 2002: Great Lakes continuous GPS (CGPS) network for geodynamics, meteorology and safe navigation. Weikko A. Heiskanen Symposium In Geodesy: Celebrating 50 years in Geodetic Science at the Ohio State University, Ohio State University, Columbus, Ohio.

Tushingham, A. M., and W. R. Peltier, 1991: Ice-3G: A new global model of late Pleistocene deglaciation based upon geophysical predictions of postglacial relative sea level. J. Geophys. Res., 96, 4497-4523.

Woodworth, P. L., and R. Player, 2003: The permanent service for mean sea level: An update to the $21^{\text {st }}$ century. J. Coast. Res., 19, 2287-2295.

Zhao, D., D. Christensen, and H. Pulpan, 1995: Tomographic imaging of the Alaska subduction zone. J. Geophys. Res., 100, 6487-6504. 